\section{Successful basal cell carcinoma defect reconstruction using combination of rotation and advancement flap: Two case reports}

\author{
Khairuddin Djawad, Siswanto Wahab, \\ Airin Nurdin \\ Department of Dermatology and \\ Venereology, Faculty of Medicine, \\ Hasanuddin University, Makassar, \\ South Sulawesi, Indonesia
}

\begin{abstract}
Defects resulting from surgical procedure may be challenging to reconstruct depending on the size and location. In case of large defects, primary closure is often not possible and thus requires skin flap or graft. In such cases, skin flap is advantageous as it produces a similar color and texture with the surrounding tissue. Skin flap techniques such as advancement flap, rotation flap dan transposition flap are useful in closing small defects. In moderate to large-sized defects, especially in areas with high tension, a combination of more than one type of flap might be necessary. This report describes two cases of large defects on the temple and cheek following basal cell carcinoma excisional surgery which were successfully closed using a combination of rotation and advancement flaps. Both patients showed excellent functional and cosmetic outcome.
\end{abstract}

\section{Introduction}

Basal cell carcinoma (BCC) is the most common skin malignancy with predilection on sun-exposed areas such as the head and neck. Total excision with $5-\mathrm{mm}$ margin is the most common surgical approach. ${ }^{1}$ In order to achieve optimal aesthetic and functional outcome, defect closure should be conducted with minimal tension. ${ }^{2}$ However, when the wound is too large, excessive tension and hence unacceptable functional or cosmetic result might arise, requiring tissue-movement procedures, such as skin flap or graft.

A local skin flap is a transfer of fullthickness skin and subcutaneous tissue from an adjacent donor site into a surgical defect which maintains local blood supply via a vascular pedicle that remains connected to the donor site. An advancement flap is onedimensional sliding of tissue into a defect where the incisions are made tangentially to the defect to free neighboring tissue, with the wound edge acting as the free margin of the flap. ${ }^{2}$ A combination with rotational flap can be further done to achieve maximal cosmetic and functional result. ${ }^{3}$

We report two cases of facial BCC which showed excellent cosmetic and functional outcomes following closure with a combination of advancement and rotational flap.

\section{Case Reports}

We report two cases of a 62-year and 68-year-old male with BCC on the left lateral forehead and right cheek, respectively. After injecting local anesthesia (lidocaine in combination with epinephrine with a ratio of $1: 100 \quad 000$ and $0.1 \mathrm{mEq} / \mathrm{mL}$ sodium bicarbonate), an excision with a 5-mm margin was made from the edge of the tumor which resulted in a defect with a diameter of $3 \mathrm{~cm}$ (Figure 1A) and $3.5 \mathrm{~cm}$ (Figure 2A), respectively. In both cases, defect reconstruction was done after histopathological examination confirmed tumor-free margins.

In the first case, after the initial incision, the superior side of defect was further extended along the hairline and preauricular area down to the inferior side of the ear lobe. This was followed by Burrow's triangle excision at the superomedial, inferolateral, and subauricular region and crescentic excision in the inferomedial side of the defect (Figure 1B). These excisions functioned to prevent ear dog phenomenon, facilitate flap movement, and reduce the defect size. A wide undermining at the upper level of the subcutaneous fat to facilitate flap movement. These produced advancement flap on the medial defect and rotation advancement flap on the lateral defect.

In the second case, after the primary incision was done, an M plasty was made on the anterior defect. This flap made the defect smaller and shortened the incision at the anterior of the defect. A curvilinear incision was done from the posterior side of the defect to the lower preauricular portion which was followed by Burrow's tringle excision behind the pinna to enable rotation advancement flap and prevent dog ear phenomenon (Figure 2B). The flap was undermined and mobilized at the upper subcutaneous fat level to allow an upward rotation advancement flap.

Hemostasis procedure by ligation or electrocoagulation of bleeding vessel was done prior to closing the flap using a 5.0 monofilament. Both cases showed excellent functional and cosmetic results after four weeks and six months follow-up, respectively (Figurse 1D and 2D).
Correspondence:Khairuddin Djawad, J1 Perintis Kemerdekaan Km. 11, Makassar, South Sulawesi 90245, Indonesia.

Tel.: +62.812-4120-2030.

E-mail: duddin@ymail.com

Key words: Basal cell carcinoma, reconstruction, rotation flap, advancement flap, combination.

Acknowledgements: The authors would like to thank Prof. Lawrence Field, Michael Goldman, MD, and Todd Holmes, MD for their kind advise and suggestions.

Contributions: $\mathrm{KD}$, was the attending physician and the operator of this case, conducted literature review, wrote, and reviewed the manuscript. SW conducted literature review, wrote, and approved the final the manuscript. AN provided expert opinion, supervised the manuscript writing process and critically reviewed the manuscript.

Conflict of interests: The authors declare no potential conflict of interest.

Funding: None.

Ethics approval: Received

Consent to publication: Received.

Please cite this article as: Djawad K, Wahab $S$, Nurdin A. Successful basal cell carcinoma defect reconstruction using combination of rotation and advancement flap: two case reports. Dermatol Rep 2021;13:9087.

Received for publication: 27 January 2021. Accepted for publication: 20 April 2021.

This work is licensed under a Creative Commons Attribution-NonCommercial 4.0 International License (CC BY-NC 4.0).

C Copyright: the Author(s), 2021

Licensee PAGEPress, Italy

Dermatology Reports 2021; 13:9087

doi:10.4081/dr.2021.9087

\section{Discussion}

The aims of BCC treatment are complete tumor removal, maximal preservation of function, and satisfying cosmetic outcome. The face is one of the sites most commonly affected with skin tumors. Defects resulting from tumor removal may have various patterns depending on the size and location of the lesion. An ideal facial reconstruction must provide good color and texture match with the surrounding tissues. Local flaps are the treatment of choice to 
repair defects of the forehead and cheek. However, the use of local flaps is often limited by tissue availability and defect size. Thus, larger defects are best treated with regional or distant flaps. A combination of flap can thus be a good option to repair a complex defect. ${ }^{4}$

The lateral forehead is one of the esthetic units in forehead which runs laterally from the midpupil to the eyebrows. It is superiorly limited by scalp, laterally by the temple and inferiorly by the eyebrow, Donor flap area for defects in this site come from temple and/or paramedian forehead area. The goals of reconstruction in this area are to maintain symmetric position of eyebrow, place scar in hairline, and maintain natural position of the temple. In the first case, defect reconstruction was done using a combination of skin from the temple and locally from the medial aspect of defect. The incision was placed in a curvilinear fashion along the hairline and eyebrow. Blunt dissection of temporal skin was conducted in the subcutaneous plane to prevent injury of the temporal branch of the facial nerve in the zygomatic area.

Utilization of two opposing flaps was aimed at reducing the defect size by recruiting skin from two separate areas of the forehead. Excision of Burow's triangle functioned to approximate the defect and, more importantly, to facilitate motion for the subsequent rotational flap. ${ }^{5}$ Reconstruction in case 2 used M-plasty, another type of advancement flap. Originally developed by Richard Webster, MD, this approach aids in distributing tension and reducing the length of the excision, hence minimizing the scar. ${ }^{6}$

Elliptical excision may be used to close small defects at the zygomatic area of the cheek. The closure of defects located on the medial zygoma may cause distortion of the eyelid. On the second case, the defect was placed in medial zygoma. As the defect was located near the periorbital area, an M-plasty to prevent extension of the excision to lower eyelid that may cause eyelid retraction was required. ${ }^{7}$

Dissection in this area had to be done carefully due to the relatively superficial location of the temporal branch of facial nerve. This branch of facial nerve crosses the zygomatic arch $2 \mathrm{~cm}$ posterior to the anterior section of the zygomatic arch. In order to avoid nerve injury, it is recommended to conduct blunt dissection above the temporoparietal fascia of the superficial subcutaneous fat. Large zygomatic defects $(\geq 3 \mathrm{~cm})$ often require reconstruction with transposition or rotation advancement flaps. ${ }^{7}$

Rotation advancement flap has a great benefit in the closure large defect in terms

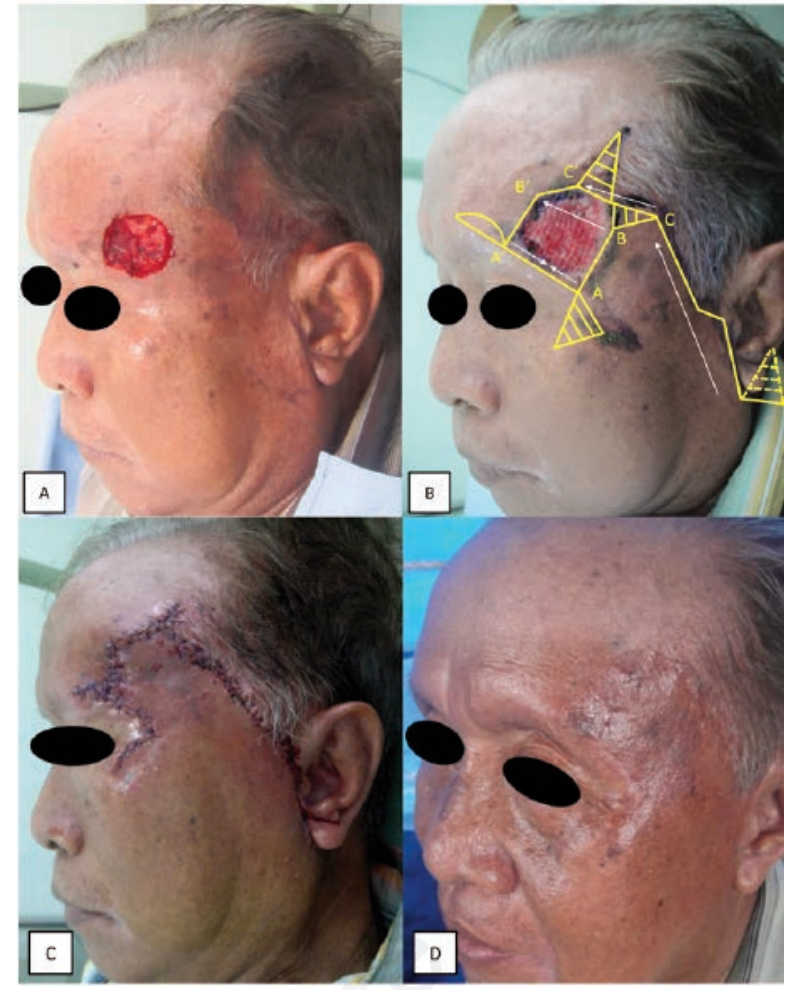

Figure 1. (A) Initial lesion; (B) Burow's triangle advancement flap in the medial, infraorbital, and sub auricular region was done to approximate defects and facilitating movement for the subsequent rotational flap; (C) Immediate post-operative result (D) Followup after four weeks showed excellent functional and cosmetic results.

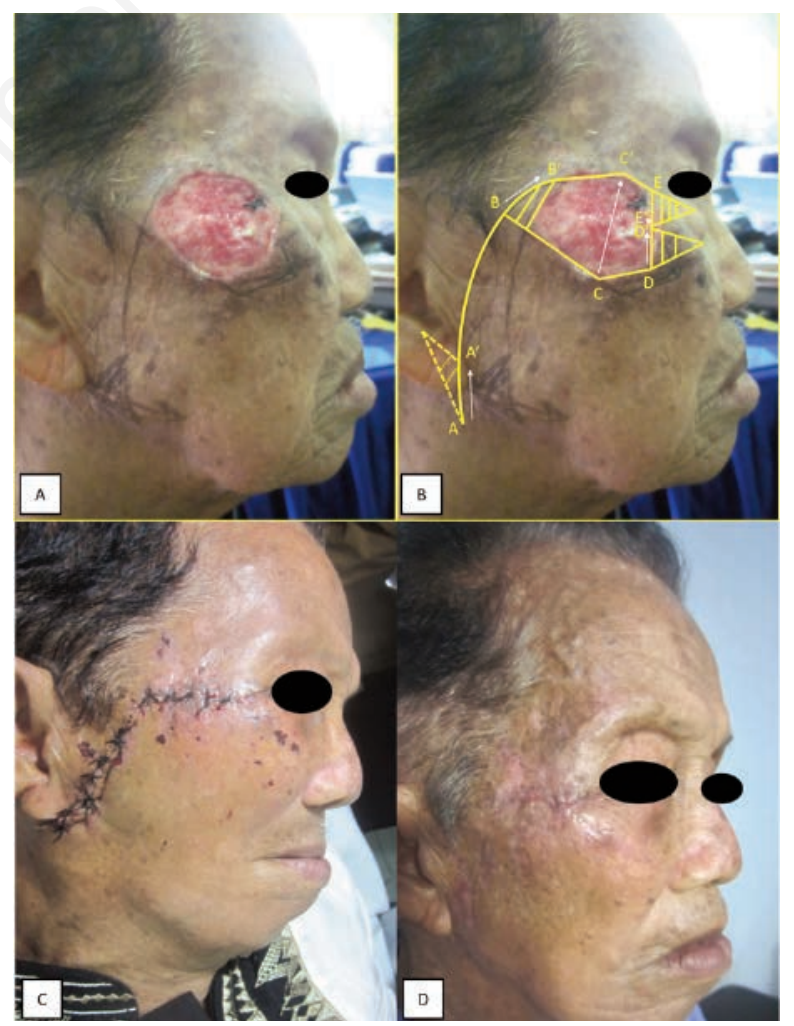

Figure 2. (A) Initial lesion; (B) M-plasty advancement flap followed by rotational flap to achieve complete defect reconstruction; (C) Immediate post-operative result (D) Result after four weeks showing excellent functional and cosmetic result after six months. 
of mobility of mid and lateral cheek. The subcutaneous fats are highly vascularized, creating a mobile pedicle. The flap was advanced and rotated superiorly. A standing tissue cone was removed behind the ear. The tension of this flap repair was directed vertically onto the lateral temple, which provided a firm anchor for the repair. ${ }^{8}$

Since advancement flap alone was not sufficient to achieve complete defect reconstruction, a combination of rotation and advancement flaps was used in both cases. Rotation flap is semi-circular in shape and rotates around a pivot point to the defect. It is particularly useful when the intended donor site of the flap is the lateral aspect of the face. Rotation flap is an alternative for moderate-sized defects of the lateral forehead regions since they have a wide base and thus an excellent blood supply. ${ }^{9}$ However, they require relatively extensive cutting beyond the defect to develop the flap, thus increasing the risk of nerve damage and bleeding. Combination of both flaps proved to be successful in accomplishing the necessary coverage without excessive tension and resultant distortion. ${ }^{10}$

\section{Conclusions}

Facial defects resulting from skin tumor may require various reconstruction approaches depending on the size and location. Both cases in this report show that the combination of flaps achieved optimum functional and aesthetic result.

\section{References}

1. Nakayama M, Tabuchi K, Nakamura Y, Hara A. Basal cell carcinoma of the head and neck. J Skin Cancer 2011;2011:496910.

2. Haimovic A, Sheehan JM, Rohrer TE. Excisional Surgery and Repair, Flaps, and Grafts. In: Kang S, Amagai M, Bruckner AL, et al., eds. Fitzpatrick's Dermatology 9th Ed. New York: McGraw-Hill Education; 2019. p. 31027.

3. Lee J, Oh SJ, Jung SW, Koh SH. Combined rotation and advancement flap reconstruction for a defect of the upper lip: 2 cases. Arch Plast Surg 2012;39:244-8.

4. Tan O. An algorythmic approach to restoration of the fronto-naso-periorbital skin defects using the forehead flaps. J Craniomaxillofac Surg 2010;38:11-8.

5. Kruter L, Rohrer T. Advancement Flaps. Dermatol Surg 2015;41:S239-46.

6. Webster RC, Davidson TM, Smith RC, et al. M-plasty techniques. J Dermatol Surg Oncol 1976;2:393-6.

7. Bhrany AD, Bradley DT, Murakami CS. Reconstruction of the cheek. In: Baker SR, editor. Local Flaps in Facial Reconstruction 3rd ed. Philadelphia: Elsevier Saunders; 2014. p. 530-62.

8. Goldman G, Dzubow L, Yelverton C. Facial Flaps Surgery: McGraw-Hill Education; 2012.

9. Shilpa K, Divya G, Budamakuntla L, Lakshmi D. Scalp defect reconstruction with triple rotation flap: A case report. J Cutan Aesthet Surg 2018;11:26-8.

10. Field LM, Dachow-Siwiec E, Szymanczyk J. Combining Flaps: Medial Canthal/Lateral Nasal Root Reconstruction Utilizing Glabellar "Fan" and Cheek Rotation Flaps: An O-to-Z Variation. J Dermatol Surg Oncol 1994;20:205-8. 